\title{
INCREASE OF THE FATIGUE LIFE OF STAINLESS STEEL BY LASER SHOCK PEENING
}

\author{
Zbyněk Špirit $^{1,2}$, Jan Kaufman ${ }^{3}$, Josef Strejcius ${ }^{1}$, \\ Michal Chocholoušek ${ }^{1}$ and Josef Kott ${ }^{1}$

\begin{abstract}
${ }^{1}$ Centrum výzkumu Rez s.r.o., Morseova 1245/6, Plzen, Czech Republic, EU; zbynek.spirit@cvrez.cz
\end{abstract} \\ ${ }^{2}$ Department of Material Science and Technology, University of West Bohemia, Plzen, Czech Republic, EU \\ ${ }^{3}$ Hilase, Institute of Physics of the ASCR, v.v.i. Czech Republic
}
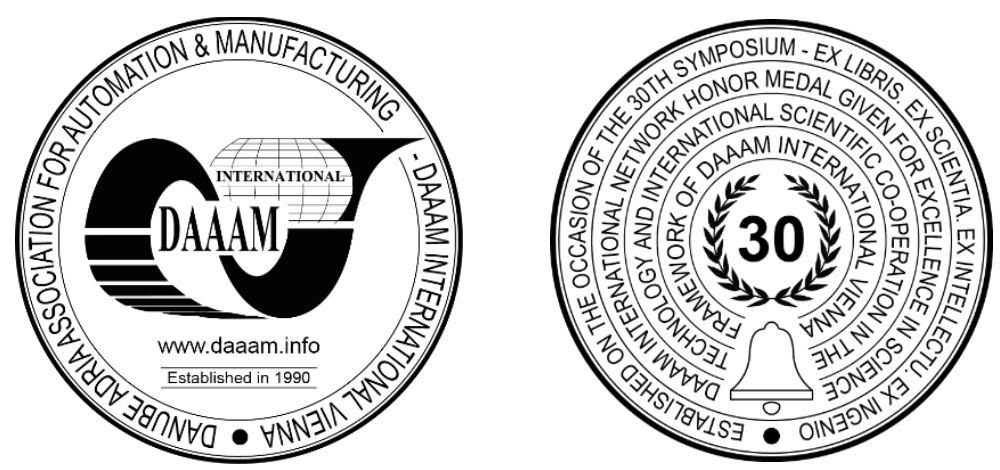

This Publication has to be referred as: Spirit, Z[bynek]; Kaufman, J[an]; Strejcius, J[osef]; Chocolousek, M[ichal] \& Kott, J[osef] (2019). Increase of the Fatigue Life of Stainless Steel by Laser Shock Peening, Proceedings of the 30th DAAAM International Symposium, pp.0826-0831, B. Katalinic (Ed.), Published by DAAAM International, ISBN 9783-902734-22-8, ISSN 1726-9679, Vienna, Austria DOI: $10.2507 / 30$ th.daaam.proceedings.114

\begin{abstract}
Laser Shock Peening (LSP) is an innovative non-contact surface treatment for improving mechanical properties of metal components. The principle of LSP is based on conversion of laser energy into shock wave that results in material plastic deformation and redistribution of residual stresses. The residual stresses increase can improve fatigue life, resistance of stress corrosion cracking, fretting properties and resistance to abrasive damage. The paper presents results of fatigue life testing of $08 \mathrm{CH} 18 \mathrm{~N} 10 \mathrm{~T}$ stainless steel and results of residual stress measurements before and after surface treatment on the stainless steel.
\end{abstract}

Keywords: Laser Shock Peening; fatigue life; residual stress; stainless steel.

\section{Introduction}

The LSP is one of surface treatments whose principle was firstly formulated by the American scientist Whitem at the end of the 20th century in the USA. The first application of LSP technology began at the end of the 90's in the military and aerospace industries [1]. LSP basically achieves similar effects as conventional shot peening (SP) treatments existing in the industry for over six decades. In traditional SP process, metallic, ceramic or glass balls acting as a miniscule ballpeen hammers make a small indentation on the metal surface on impact. The advantages over LSP are that it is cheap, it uses robust process equipment and it can be applied on large or small areas as required. The disadvantages of SP are that the process is semi-quantitative. This method cannot guarantee uniform and accurate SP intensity across the treated area. The next limitation of SP is that the depth of compressive residual stress usually does not exceed $0.25 \mathrm{~mm}$ in soft metals. Moreover, the surface roughness after SP is worse when compared to LSP [1, 2]. LSP process in comparison can produce a compressive residual stress more than $1 \mathrm{~mm}$ in depth, which is at least four times deeper than the traditional SP process. SP may also damage the surface finish of metal components and can easily cause distortion of thin section, whereas the surface of a component treated with LSP loses little dimensional accuracy [3]. 
The principle of LSP is based on conversion of laser energy into a shock wave that results in material plastic deformation and redistribution of residual stresses. When the high energy laser pulses of short nanosecond durations focus on a water immersed metal material, the top surface (sacrificial layer) absorbs the laser energy and evaporates instantaneously through ablative interaction, as shown in figure 1. The resulting high-density vapor is immediately ionized (multiphoton ionization and avalanche ionization) and forms a plasma plume which absorbs the rest of the laser pulse via the inverse Bremsstrahlung mechanism, the absorption of high-intensity radiation by electrons in the field of nuclei [5, 6]. High pressure of the expanding plasma generates a shock wave, which impinges on the surface of the metal material with an intensity of several GPa, far exceeding the yield strength of the metal. The shock wave propagates into the metal interior and loses energy as it creates a permanent strain on the metal material. The permanent strain remains after the shock wave passage. The strained region is subsequently constrained with surrounded metal material as a reaction to elastic strain, thus forming a compressive residual stress on the metal surface [5].

The LSP technology is used as a substitute for SP conventional treatments where higher standard of fatigue performance is required. The LSP technology can be used on a wide type of materials as aluminium alloys [7], steel [8] and copper alloys [9], nickel alloys [10], magnesium alloys [11], amorphous metals [12] and others.

1.

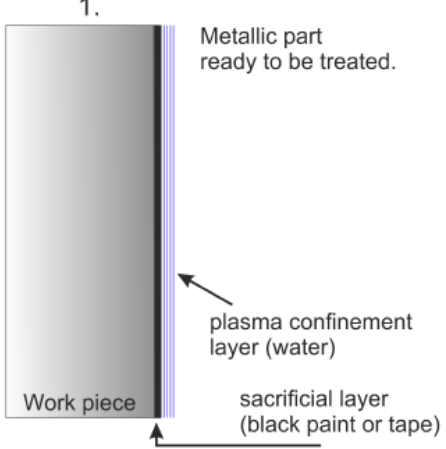

4.

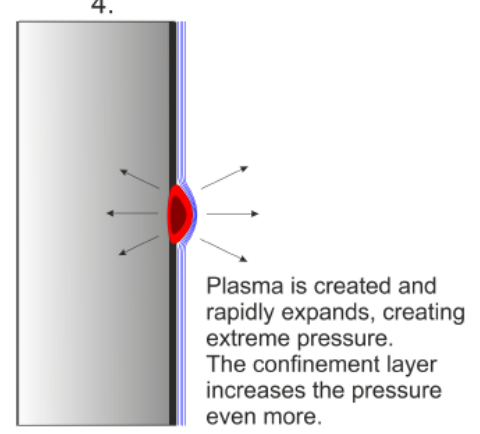

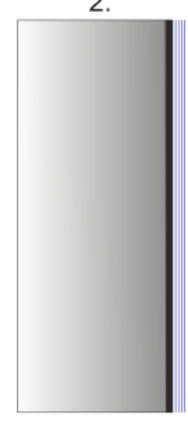

5 .

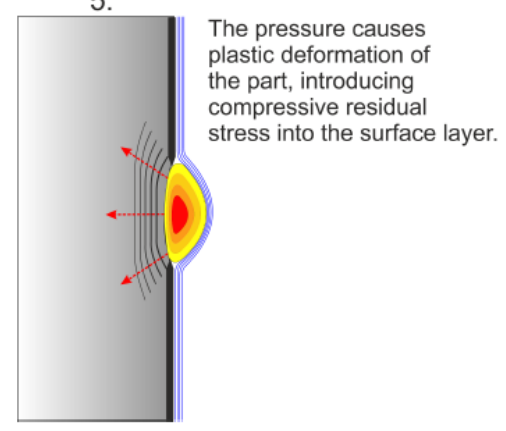

Q-switched laser beam pulse is focused onto the sample.

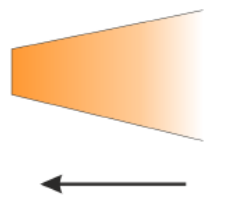

6.

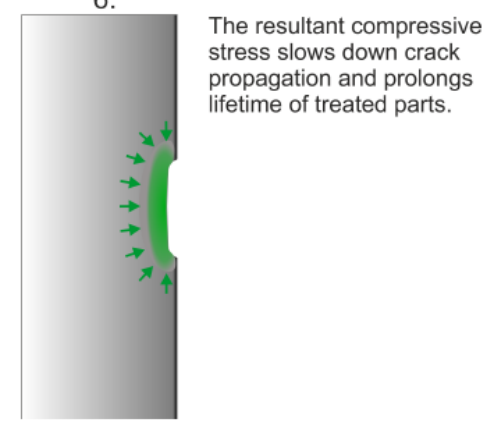

Laser beam passes through the confinement layer and is absorbed in the sacrificial layer.

Fig. 1. Description of the LSP process [4]

\section{Experimental procedure}

The aim of experiment is to increase the fatigue life of specimens by LSP treatment. The High Cycle Fatigue (HCF) - three-point bending (3PB) test was performed to determine the fatigue life of the material. The testing material was austenitic stainless steel $08 \mathrm{CH} 18 \mathrm{~N} 10 \mathrm{~T}$. The chemical composition is in table 1 . Specimens for HCF test were manufactured from the material in accordance with the drawing design in figure 2 . The specimens were manufactured by Electric Discharge Machining (EDM) with $1 \mathrm{~mm}$ depth notch, as shown in figure 2. The specimen's sides were ground to roughness $\mathrm{Ra} 0.8 \mu \mathrm{m}$.

\begin{tabular}{|c|c|c|c|c|c|c|c|c|c|c|c|}
\hline Material & $\begin{array}{c}\mathrm{Fe} \\
\text { [wt.\%] }\end{array}$ & $\begin{array}{c}\mathrm{C} \\
\text { [wt.\%] }\end{array}$ & $\begin{array}{c}\mathrm{Mn} \\
{[\mathrm{wt} . \%]}\end{array}$ & $\begin{array}{c}\mathrm{Si} \\
\text { [wt.\%] }\end{array}$ & $\begin{array}{c}\mathrm{P} \\
\text { [wt.\%] }\end{array}$ & $\begin{array}{c}\mathrm{S} \\
\text { [wt.\%] }\end{array}$ & $\begin{array}{c}\mathrm{Cr} \\
\text { [wt.\%] }\end{array}$ & $\begin{array}{c}\mathrm{Ni} \\
\text { [wt.\%] }\end{array}$ & $\begin{array}{c}\mathrm{Cu} \\
\text { [wt.\%] }\end{array}$ & $\begin{array}{c}\text { Mo } \\
\text { [wt.\%] }\end{array}$ & $\begin{array}{c}\mathrm{Ti} \\
\text { [wt.\%] }\end{array}$ \\
\hline 08CH18N10T & - & 0.05 & 1.68 & 0.57 & 0.02 & 0.001 & 17.5 & 9.9 & 0.06 & 0.06 & 0.47 \\
\hline
\end{tabular}

Table 1. Chemical composition of stainless steel 08Ch18N10T 


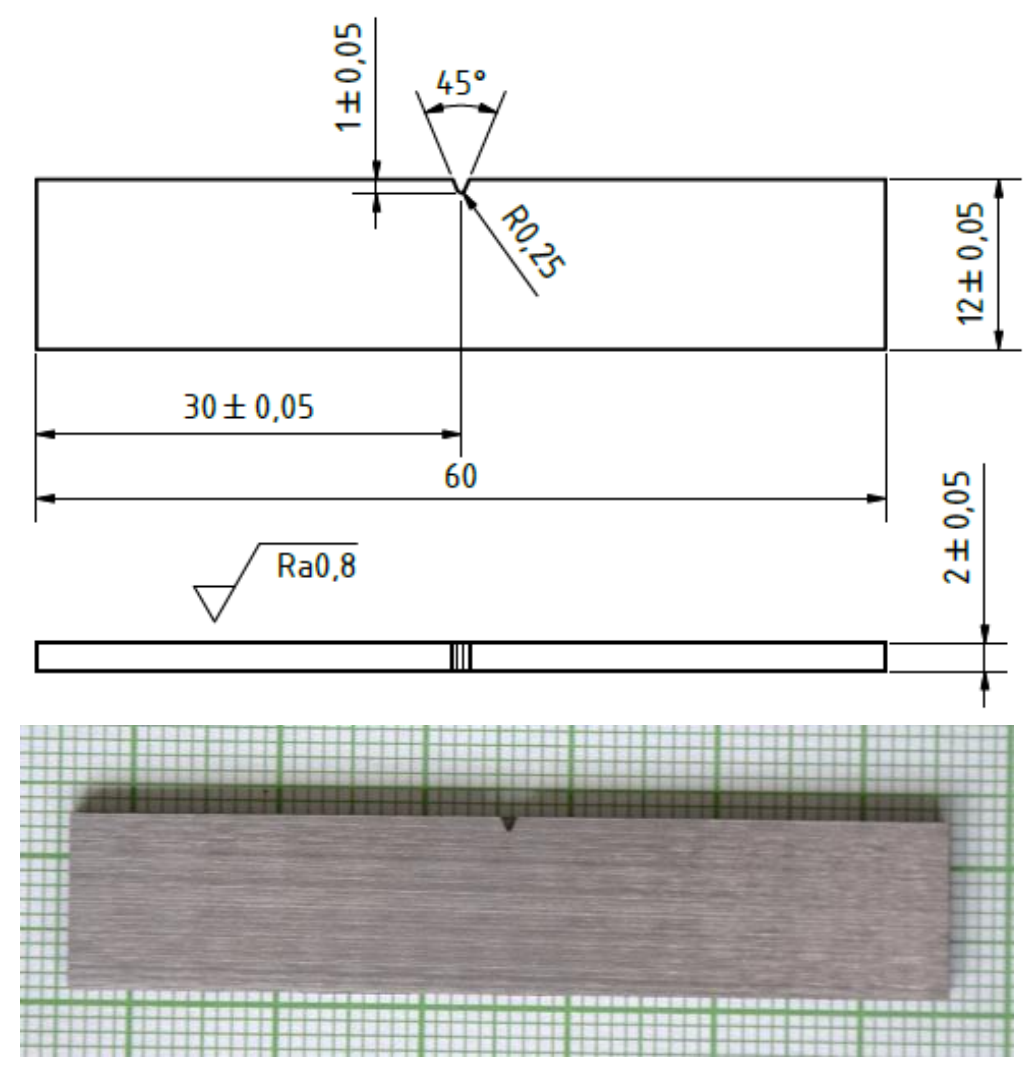

Fig. 2. Specimen for HCF three-point bending test.

The maximum tensile stress area in the specimen at three-point loading is under the notch. Therefore, the goal of LSP sequence was to increase the compressive residual stress (RS) under the notch. The sequence of shots was performed as shown in figure 3 . The first shots in first sequence are red colour and every shot start from left side to right direction (see figure 5). The next shots in the second row are blue colour and sequences are shifted $1 \mathrm{~mm}$ up. The last shots in the eighth row are green.

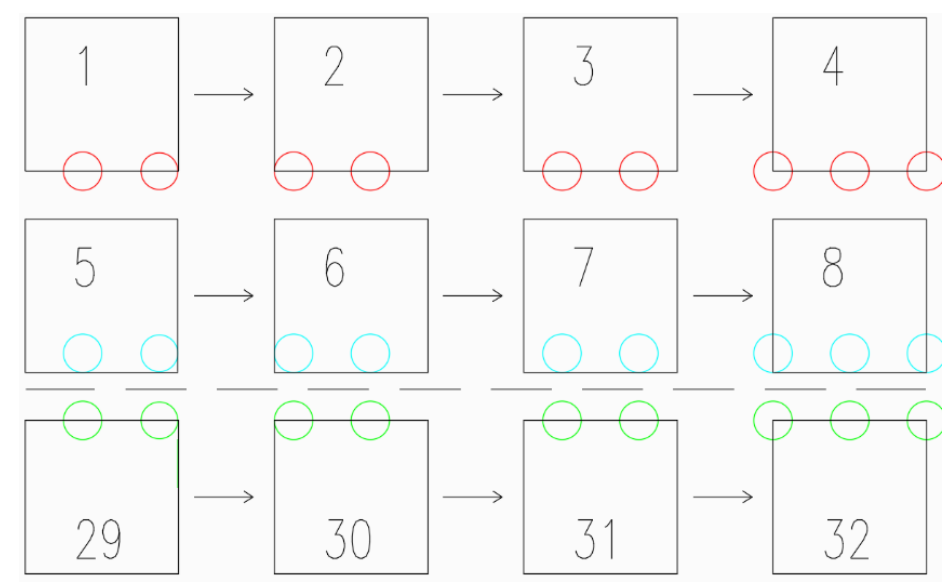

Fig. 3. Laser shot sequence in patch area.

The specimen surfaces were treated from both sides using L2 system - BIVOJ (HiLASE Centrum, CZ) [13] with a wavelength of $1030 \mathrm{~nm}$, pulse duration $10 \mathrm{~ns}$, maximum energy $100 \mathrm{~J}$ and frequency $10 \mathrm{~Hz}$. The laser parameters of surface treatment are: energy in pulse $2.5[\mathrm{~J}]$, beam diameter $2[\mathrm{~mm}]$, power density $6.25\left[\mathrm{GW} / \mathrm{cm}^{2}\right]$, overlap $50[\%]$ and vinyl tape. The dimension of LSP patch was $8 \times 8 \mathrm{~mm}$.

After manufacturing specimens and LSP treatment, RS was measured by XRD machine in three areas below the notch (see figure 4). These areas are significant for the fatigue crack propagation. 


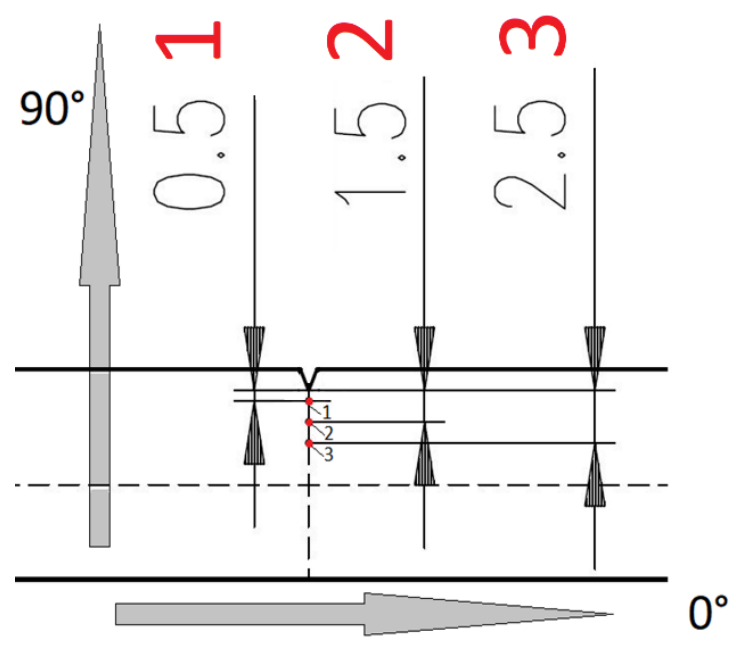

Fig. 4. Location of RS measured areas.

Fatigue tests were performed in load control on Electromagnetic pulsator for HCF testing - RUMUL. Table 4 shows the testing parameters. RS were measured on XRD machines RIGAKU AutoMATE II with parameters tube $-\mathrm{Cr} / \mathrm{K}$ alpha 1 / $40 \mathrm{kV} / 40 \mathrm{~mA}$, peak angle $-129.15 \mathrm{deg}$, collimator $-2 \mathrm{~mm}$, meas. method - iso-inclination, Psi0, oscillate -5 deg.

\begin{tabular}{|c|c|c|c|c|c|}
\hline Load & $\begin{array}{c}\text { Support span } \\
{[\mathbf{m m}]}\end{array}$ & $\begin{array}{c}\text { Stress } \\
\text { ratio }\end{array}$ & $\begin{array}{c}\text { Frequency } \\
{[\mathbf{H z}]}\end{array}$ & $\begin{array}{c}\text { Test } \\
\text { frequency }[\mathbf{H z}]\end{array}$ & $\begin{array}{c}\text { Temperature } \\
{\left[{ }^{\circ} \mathbf{C}\right]}\end{array}$ \\
\hline 3PB & 40 & 0.1 & $90-92$ & 20 & 22 \\
\hline
\end{tabular}

Table 2. HCF parameters

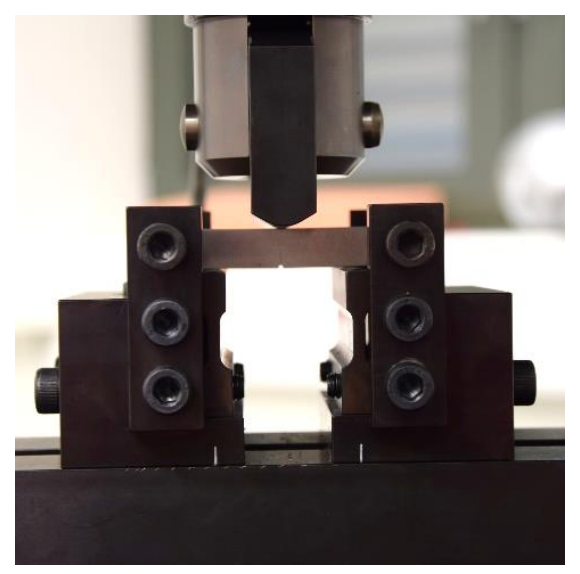

Fig. 5. HCF test layout

\section{Results}

The results of RS measuring are summarized in figure 6. The measured values show increase by more than $220 \mathrm{MPa}$ of compressive RS nearby the notch in area 1 after LSP treatment compared to unpeened material. The RS values after LSP treatment in the areas 2 and 3 are only slightly higher than compressive RS of unpeened material.

The results of fatigue life of LSP and unpeened specimens are summarized in figure 7. The value of fatigue life cycles was set to the value of delta frequency decreased by $20 \mathrm{~Hz}$ (approx. the crack propagation to the middle of the specimen). The fatigue life ( $10^{7}$ cycles) of peened specimens was evaluated at $6 \max 280 \mathrm{MPa}$ (i.e. $154 \pm 126 \mathrm{MPa}$ ) and of unpeened specimens at $180 \mathrm{MPa}$ (i.e. $99 \pm 81 \mathrm{MPa}$ ). The peened material achieved higher value of fatigue life cycles about more than $55 \%$ than unpeened specimens.

The specimen's picture after HCF test are in figure 8 and 9. The crack initiates from the notch and it grows in the notch direction. On the peened specimens, there was observed "zigzag" fatigue crack and fatigue crack on the unpeened specimens was straight as you seen figure 9 . 


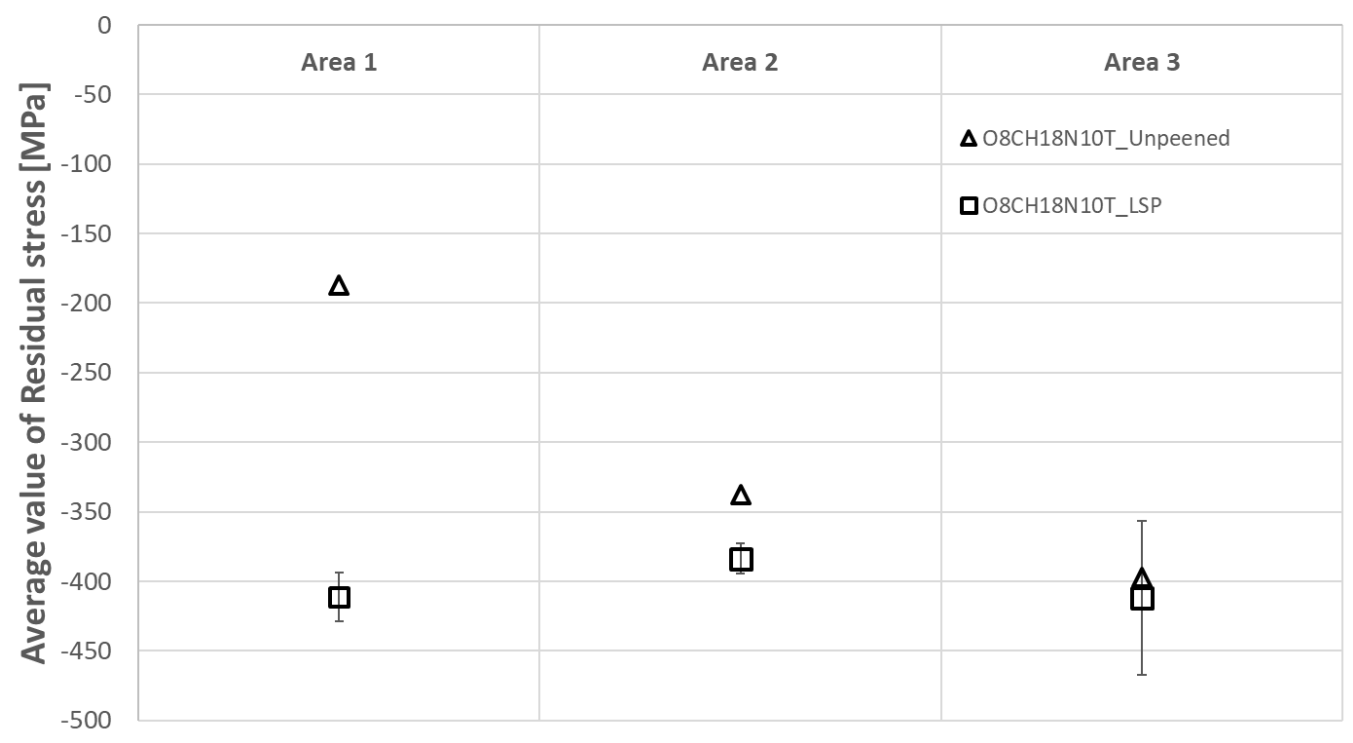

Fig. 6. RS before and after LSP treatment in 3 areas.

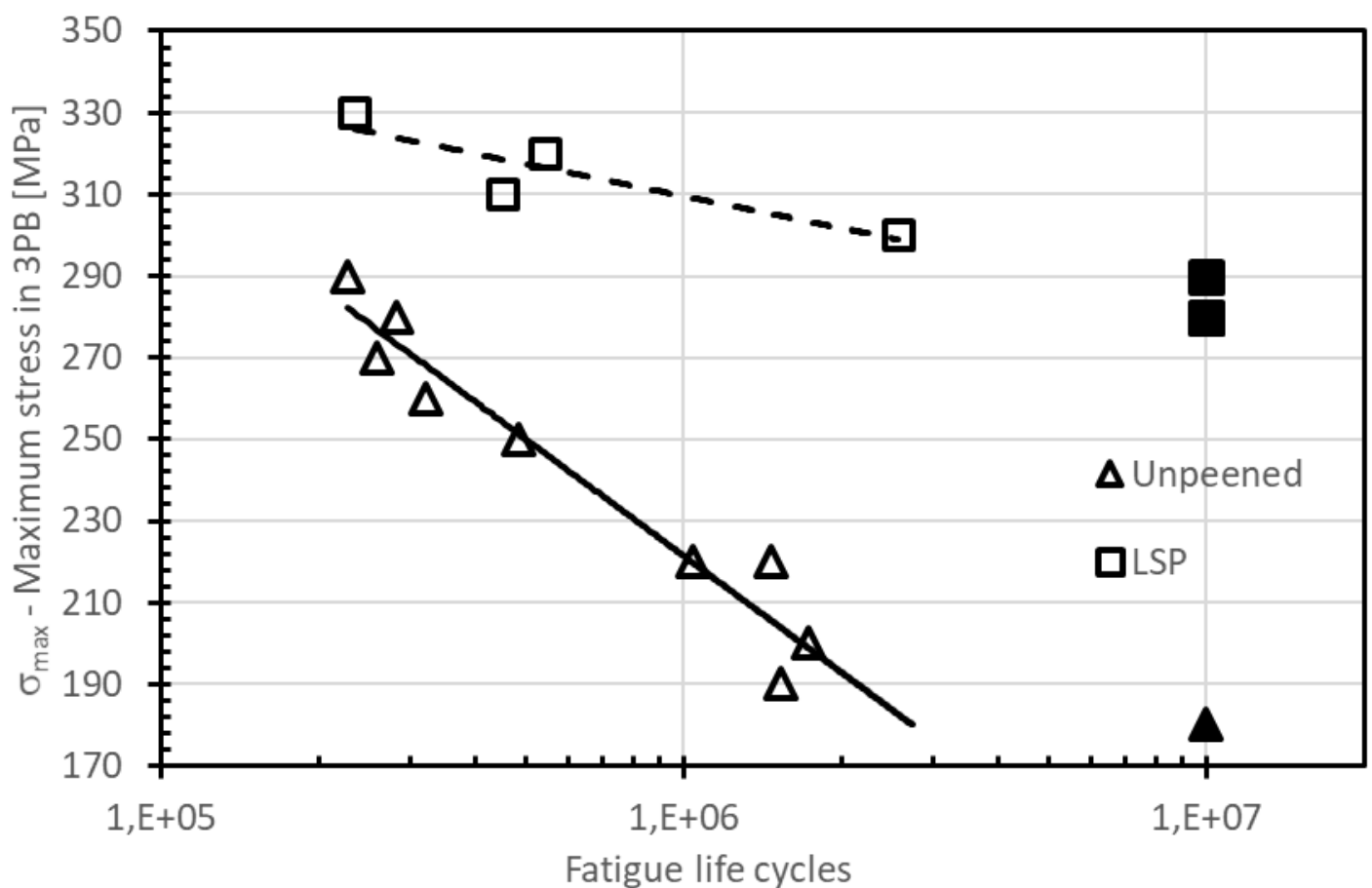

Fig. 7. Fatigue life curve of unpeened and peened specimens

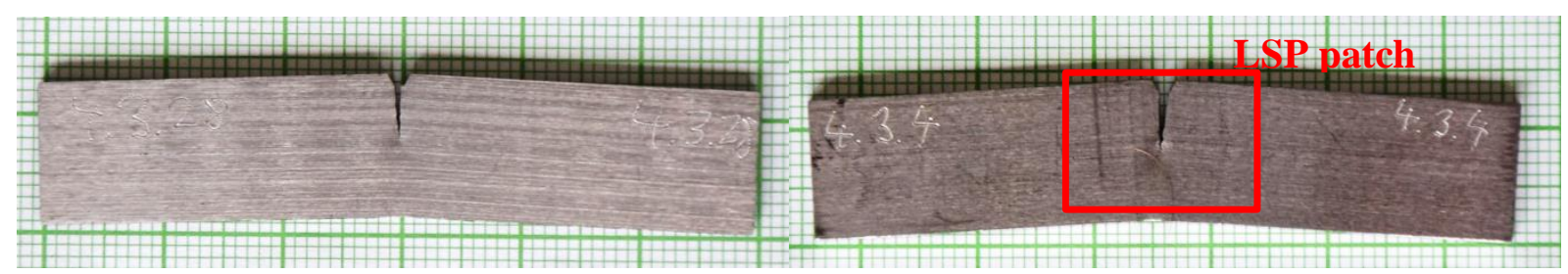

Fig. 8. Specimens after HCF test without LSP (left) and with LSP treatment (right) 


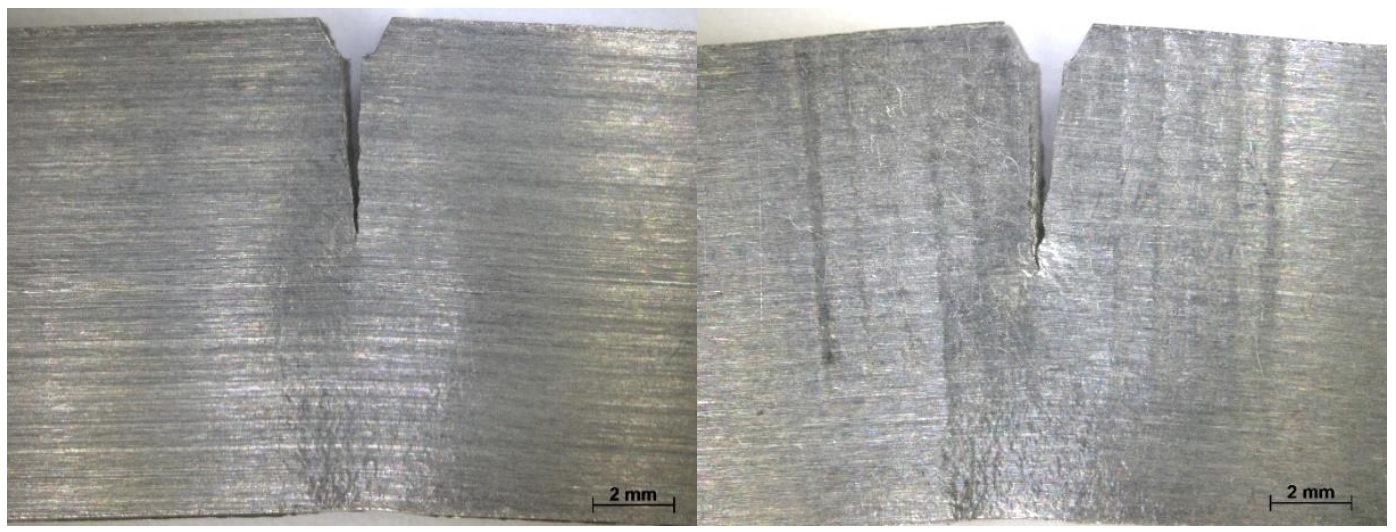

Fig.9. Fatigue crack in specimen after HCF test without LSP (left) and with LSP treatment (right)

\section{Conclusion}

The presented paper shows the results of improving the HCF performance on 3PB specimens from austenitic steel $08 \mathrm{Ch} 18 \mathrm{~N} 10 \mathrm{~T}$. The peened specimens had more than $55 \%$ higher fatigue life than unpeened specimens. The maximum compressive stress was measured nearby the notch with the value $-411 \pm 17 \mathrm{MPa}$ in the peened specimens and $-187 \pm 24$ $\mathrm{MPa}$ on the unpeened specimens in the same area. It follows from the presented results that the correctly chosen shots strategy has a fundamental influence on the distribution of residual stress and thus also on the increase in fatigue life. The microstructure analyses and measuring of residual stress for determination depth profile are in progress.

\section{Acknowledgments}

The presented work was financially supported by the Ministry of Education, Youth and Sport Czech Republic - project LQ1603 Research for SUSEN. This work has been realized within the SUSEN Project (established in the framework of the European Regional Development Fund (ERDF) in project CZ.1.05/2.1.00/03.0108 and of the European Structural and Investment Funds (ESIF) in the project CZ.02.1.01/0.0/0.0/15_008/0000293).

\section{References}

[1] Champaigne J History of Shot Peening Specifications, Ninth International Conference on ShotPeening, Spring 2006

[2] Ding K and Ye L Laser shock peening, Performance and process simulation, Woodhead Publishing on behalf of The Institute of Materials, Minerals and Mining, Cambridge England, Spring 2006

[3] Claurer A.H, Gregory J.K,. Rack H.J, and Eylon D (eds) Laser shock peening for fatigue resistance. Proceedings of Surface Performance of Titanium, TMS, Warrendale, PA. Metal Society of AIME,217-30

[4] Kaufman, J (2018). Influence of Laser Shock Peening on corrosion resistance and stress corrosion cracking of aluminum alloy 5083, Ph.D. Dissertation, Faculty of Nuclear Sciences and Physical Engineering, Czech technical university in Prague

[5] A. K. Gujba, M. Medraj, Laser Peening Process and Its Impact on Materials Properties in Comparison with Shot Peening and Ultrasonic Impact Peening, Materials 2014 (7), 10.3390/ma7127925, 2014

[6] N. Hfaiedh, P. Peyre, H. Song, I. Popa, V. Vignal, Finite element analysis of laser shock peening of 2050-T8 aluminum alloy, International Journal of Fatigue 70 (480-489), 10.1016/j.ijfatigue.2014.05.015, 2015

[7] N. Hfaiedh, P. Peyre, H. Song, I. Popa, V. Vignal, Finite element analysis of laser shock peening of 2050-T8 aluminum alloy, International Journal of Fatigue 70 (480-489), 10.1016/j.ijfatigue.2014.05.015, 2015

[8] S. Yoshihiro, S. Yuji, S. Rie, K. You-Chul, Fatigue Life Enhancement of Fillet and Butt Welded Joints after Laser Peening, Transactions of JWRI 41 (1), http://hdl.handle.net/11094/23163, 2012

[9] R.K. Thareja, S. Shukla, Synthesis and characterization of zinc oxide nanoparticles by laser ablation of zinc in liquid, Applied Surface Science 253 (8889-8895), 10.1016/j.apsusc.2007.04.088, 2007

[10] A.A. Bugayeva, M.C. Guptab, R. Payne, Laser processing of inconel 600 and surface structure, Optics and Lasers in Engineering 44 (102-111), 10.1016/j.optlaseng.2005.04.014 , 2006

[11] Y. Zhang, J. You, J. Lu, Ch. Cui, Y. Jiang, X. Ren, Effects of laser shock processing on stress corrosion cracking susceptibility of AZ31B magnesium alloy, Surface \& Coatings Technology 204 (3947-3953), 10.1016/j.surfcoat.2010.03.015, 2010

[12] J. Fu, Y. Zhu, C. Zheng, R. Liu, Z. Ji, Effect of laser shock peening on mechanical properties of Zr-based bulk metallic glass, Applied Surface Science 313 (692-697), 10.1016/j.apsusc.2014.06.056, 2014

[13] Pilar J, De Vido M, Divoky M, Mason P D (eds), Characterization of Bivoj/DiPOLE 100: HiLASE 100-J/10-Hz diode pumped solid state laser, [online] http://www.hilase.cz/?s=lsp [cit.2018-09-25] Sagar Bhamare, Gokul Ramakrishnan, Seetha R. Mannava, Kristina Langer, Vijay K. Vasudevan, 